DOI: https://doi.org/10.15688/jvolsu4.2018.4.12

UDC 327(510) + 327.7+339.1-051(5)

Submitted: 12.11 .2017

LBC Ф3(5Кит)64,0 + T3(5Кит)64-6

Accepted: 23.03.2018

\title{
EVALUATION OF CHINA'S BELT AND ROAD INITIATIVE BY EUROPEAN THINK TANKS (2013-2017) ${ }^{1}$
}

\author{
Kseniya G. Muratshina \\ Ural Federal University named after the first President of Russia B.N. Eltsin, \\ Ekaterinburg, Russian Federation
}

\begin{abstract}
This paper presents the analysis of the leading European think tanks' research on The Belt and Road Initiative (BRI) proposed by the Chinese government in 2013. We point out the most specific assessments and main trends within the existing approaches to the mentioned initiative. Since Russia is a direct participant of this project, the comparison of Russian and foreign sinologists' views seems to be important for working out a complex strategy of Russia's participation in the Chinese project with a clear understanding of China's policy and possible advantages for our country. The study has been carried out with the help of comparative analysis and historical genesis approach, which let us understand and formulate the major points of the European experts' evaluation. The selection of the think tanks, whose publications have been investigated, is conditioned by the area of their activity - international and oriental studies. The paper consequently discusses the collective monographs, reports, brochures and commentaries, issued by the think tanks of Western, Central and Eastern Europe.

The research results show that the majority of European sinologists view The Belt and Road Initiative not as a form of aid to foreign countries, but as an entirely commercial initiative serving the Chinese interests. The main reasons for BRI implementation, put forward by the EU experts include energy security, the need for the development of China's western regions, the purpose to get better access to natural resources in different regions of the world, as well as the yuan internationalization. Furthermore, BRI is definitely viewed by the European experts as a project, competing with other integration initiatives in Eurasia, primarily with the Eurasian Economic Union. Finally, the paper gives the recommendations, given by the European think tanks to their governments. In particular, the main idea is to develop the most sophisticated and scrutinized expert evaluation of all BRI projects entered by the European countries, and to differentiate among China-oriented initiatives and mutually beneficial ones.
\end{abstract}

Key words: China, The Belt and Road Initiative, Europe, sinology, think tanks.

Citation. Muratshina K.G. Evaluation of China's Belt and Road Initiative by European Think Tanks (20132017). Vestnik Volgogradskogo gosudarstvennogo universiteta. Seriya 4, Istoriya. Regionovedenie. Mezhdunarodnye otnosheniya [Science Journal of Volgograd State University. History. Area Studies. International Relations], 2018, vol. 23, no. 4, pp. 131-147. (in Russian). DOI: https://doi.org/10.15688/jvolsu4.2018.4.12

УДК $327(510)+327.7+339.1-051(5)$

ББК Ф3(5Кит)64,0 + Т3(5Кит)64-6

Дата поступления статьи: 12.11.2017

Дата принятия статьи: 23.03.2018

\section{КИТАЙСКАЯ ИНИЦИАТИВА «ОДИН ПОЯС, ОДИН ПУТЬ» В ОЦЕНКАХ ЕВРОПЕЙСКИХ ЭКСПЕРТНО-АНАЛИТИЧЕСКИХ ЦЕНТРОВ (2013-2017 гГ.) ${ }^{1}$}

\section{Ксения Геннадьевна Муратшина}

Уральский федеральный университет имени первого Президента России Б.Н. Ельцина, г. Екатеринбург, Российская Федерация

Аннотация. В статье представлен анализ работ специалистов ведущих европейских экспертно-аналитических центров, работающих в области востоковедения и международных исследований, по выдвинутому в 2013 г. Китайской Народной Республикой проекту «Один пояс, один путь» (ОПОП). Выявляются наиболее специфичные оценки и основные тренды в подходах к рассмотрению существа проекта. В силу того, что Россия также является непосредственным участником ОПОП, сопоставление различных оценок и данных, 


\section{ПОЛИТИЧЕСКИЕ НАУКИ И РЕГИОНОВЕДЕНИЕ}

полученных российскими и зарубежными синологами, важно для выработки комплексной стратегии участия страны в данном китайском проекте с максимально четким пониманием политики Китая и возможной выгоды для собственного развития. В рамках статьи последовательно изучены аналитические доклады, индивидуальные и коллективные брошюры и комментарии, опубликованные научными центрами как Западной, так и Центральной и Восточной Европы. В результатах исследования отмечается, что большинство европейских синологов рассматривают ОПОП не в качестве формы помощи КНР другим странам, а как чисто коммерческое начинание, работающее в большинстве случаев исключительно на китайские интересы; выделяются рассматриваемые европейскими авторами предпосылки, проблемы и факторы развития ОПОП, а также восприятие его как проекта, конкурирующего с другими интеграционными инициативами на евразийском пространстве, в первую очередь с Евразийским экономическим союзом. Также выделены рекомендации, которые европейские синологи адресуют политикам своих стран, в первую очередь это более тщательная экспертиза планов участия в ОПОП и проведение четкого разграничения между проектами, в которых выгоду может получить один Китай, и возможными взаимовыгодными инициативами.

Ключевые слова: Китай, проект «Один пояс, один путь», Европа, китаеведение, экспертно-аналитические центры.

Цитирование. Муратшина К. Г. Китайская инициатива «Один пояс, один путь» в оценках европейских экспертно-аналитических центров (2013-2017 гг.) // Вестник Волгоградского государственного университета. Серия 4, История. Регионоведение. Международные отношения. - 2018. - Т. 23, № 4. - С. 131-147. - DOI: https://doi.org/10.15688/jvolsu4.2018.4.12

\section{Введение}

После выдвижения Китаем в 2013 г. инициативы возрождения Шелкового пути в целях расширения торгово-экономического сотрудничества со странами всего Евразийского континента, в мировом востоковедении и международных исследованиях, в том числе в России, появилось большое количество разнообразных оценок проекта и прогнозов относительно его развития. В данном исследовании выявлены и проанализированы оценки, изложенные в работах специалистов ведущих экспертно-аналитических центров Западной, Центральной и Восточной Европы, занимающихся востоковедческой и международной проблематикой. Китаеведение в настоящее время можно назвать одним из наиболее быстро развивающихся научных направлений в европейских международных исследованиях. В этой сфере работают профессионалы высокого класса, и, как можно сделать вывод после участия в серии мероприятий, проводившихся научными центрами ЕС, и контактов и обменов с европейскими коллегами, данное направление не испытывает недостатка в финансировании и имеет все возможности для проведения разнообразных исследований комплексного, перспективного характера.

Стоит упомянуть, что как российскими аналитиками (например, В.Б. Кашиным [3] и И.Е. Денисовым из Института Дальнего Во- стока РАН [2], А.Т. Габуевым из Московского Центра Карнеги [1]), так и европейскими (например, специалистами Стокгольмского института исследований проблем мира [24, p. 11]) отмечалось, что Китай в настоящее время, «вбросив» проект на международное обсуждение, относит к его реализации многие проекты в той же Центральной Азии, но при этом воздерживается от предоставления большего количества официальной информации. Не существует даже полной официальной карты со всеми маршрутами нового Шелкового пути, которая была бы обнародована органами власти КНР. Представляется, что анализ палитры мнений, высказанных европейскими китаеведами, складывание своеобразной мозаики из оценок и свидетельств могут быть полезны для более четкого понимания того, что представляет из себя проект, в котором Россия приготовилась активно участвовать. Что касается планов России и всей совокупности взглядов российской стороны на китайский проект, то этот вопрос требует отдельного исследования.

\section{Методы}

В данном исследовании применяются преимущественно такие методы, как историко-сравнительный и историко-генетический, позволяющие осуществить компаративный анализ различных точек зрения и объяснить 
причины появления тех или иных оценок. Историография вопроса - то есть рассмотрения экспертными центрами Европейского союза китайской стратегии «Один пояс, один путь» в данной статье является непосредственным объектом изучения. Ранее подобного анализа в российских международных исследованиях и востоковедении не проводилось. Также выбор объекта исследования обусловлен важностью учета выводов европейских специалистов в качестве некоего взгляда со стороны на проблему в условиях повсеместного присоединения стран, в том числе России, к проекту, выдвинутому КНР.

Наконец, стоит оговориться, что существуют различные варианты названия рассматриваемой китайской инициативы, первоначально часто встречались отдельные термины «Экономический пояс Шелкового пути» и «Морской Шелковый путь XXI в.» для разных ее направлений, в настоящее же время чаще начали применяться наименования «Один пояс, один путь» или «Инициатива Пояса и Пути». В данной работе для удобства и единообразия будет использоваться обозначение «Один пояс, один путь» (ОПОП).

\section{Анализ}

Пожалуй, особенно значимым из крупных экспертно-аналитических структур Западной Европы является Европейский совет по международным отношениям (ECFR). Первое крупное комплексное исследование ECFR по ОПОП - доклад «“One Belt, One Road": China's Great Leap Forward» - было опубликовано в 2015 г. Главным, на что обращает внимание эта работа, стали следующие моменты: недостаток обнародованной конкретики в планах КНР, их долгосрочность (период полной имплементации проекта оценивается в 35 лет), «большие ожидания» остального мира от проекта. Основным инструментом продвижения китайской стратегии в отношениях с партнерами называется предоставление Пекином кредитов. Создаваемая в рамках ОПОП инфраструктура нацелена на улучшение условий экспорта товаров из Китая и получения им природных ресурсов из других стран. В то же время высказывается мнение, что инвестиции КНР в «рискованные» проекты в странах вдоль ОПОП, находящихся в сложной экономической ситуации, могут столкнуться с неожиданными и большими проблемами. Наконец, идея «единой судьбы» для всей Азии, продвигаемая китайской стороной в рамках ОПОП, является, в понимании экспертов ECFR, экспансионистской с геополитической точки зрения [32].

Тезис о решении Китаем задач получения доступа к сырьевым ресурсам соседних стран и экспорта избытков своей продукции и промышленных мощностей в рамках ОПОП повторяется и в соответствующих тематических разделах опубликованного ECFR в 2016 г. масштабного исследования «Connectivity Wars», посвященного различным аспектам соперничества между ведущими акторами международных отношений в торговой и транспортной сфере. В нем без лишних экивоков утверждается в некотором роде неомарксистский взгляд на ОПОП: отмечается, что этот проект создает такую структуру партнерства, при которой страны становятся зависимыми от Китая, он «может их эксплуатировать», и такая структура полностью отражает неомарксистскую модель «центр - периферия» [16, p. 21-22]. Кроме того, указывается, что в качестве инструмента для развития ОПОП Китаем используются самые разные интеграционные структуры - например, Шанхайская организация сотрудничества, БРИКС, Азиатский банк инфраструктурных инвестиций. Пекин не разрушает мировой порядок и устоявшуюся систему международных организаций, а создает свою, «параллельную», «теневую». Благодаря наличию таких «параллельных» структур Китай в своем стремлении «восстановить статус мировой державы» «старается не повторить ошибок, допущенных в своем возвышении Германией и Японией в XX в.» и «избежать ситуации, в которой ему пришлось бы лицом к лицу помериться военной силой с уже утвердившимися мировыми державами» [16, p. 88-89].

Также некоторые оценки ОПОП высказываются специалистами ECFR в отдельных коллективных и индивидуальных докладах и комментариях. В исследовании 2016 г., посвященном евразийской интеграции, отмечается, что ОПОП - это «амбициозный проект», конкурирующий с ЕАЭС - «геополитическим 
блоком, в котором доминирует Россия». ОПОП нацелен на то, чтобы «использовать финансовую мощь Китая для экономической интеграции Евразии, центром которой будет KHР». Очень точно аналитиками ECFR подмечены риски для производителей в ЕАЭС в случае проникновения большого количества дешевых китайских товаров в условиях слабого контроля границ центрально-азиатских государств с КНР и коррупции внутри ЕАЭС. Интересно сравнение товарных и производственных стандартов ЕАЭС и ОПОП: стандарты ЕАЭС называются более близкими к европейским и строгими, по сравнению с тем, что предлагает в рамках своих проектов сотрудничества Китай. На практике это означает, что рынки всех стран, вошедших в проект, окажутся буквально заваленными дешевыми китайскими товарами, в том числе менее качественными, чем продукция других государств и собственных производителей, которые неизбежно понесут убытки. Наконец, в докладе подчеркивается тщетность «культивирования» Россией, в контексте участия в ОПОП, образа Китая как «союзника» в ее противостоянии с «идеей возглавляемого США однополярного мирового порядка». Более того, эксперты ECFR отмечают, что «Пекин не может дать Москве то, в чем она нуждается, - доступа к технологиям, необходимым для модернизации экономики», и «не может заменить в этой роли Европу». Логичный вывод, к которому приходят авторы доклада, состоит в том, что ОПОП и ЕАЭС «не являются абсолютными конкурентами, но в то же время и не являются совместимыми» [22].

В докладе 2016 г. «China's investment in influence: the future of $16+1$ cooperation», посвященному сотрудничеству Китая со странами Центральной и Восточной Европы по схеме «16+1», высказывается мнение о том, что Пекин может использовать ОПОП в том числе для придания нового импульса отношениям именно с этой группой стран, причем, по сути, в обход Брюсселя, также решая свои задачи по участию в инфраструктурных, логистических проектах и увеличению товарного экспорта [15]. Опасения европейской стороны теоретически можно понять: такая модель сотрудничества, скорее всего, будет спо- собствовать расширению наметившихся трещин между «старой Европой» и восточно-европейскими членами союза.

Руководитель программы изучения Азии и Китая в ECFR, крупнейший французский синолог Ф. Годман называет ОПОП «баннером», под которым объединены все новые проекты Китая в соседних с ним странах Азии [23], и, подобно психоаналитику, ищет корни проекта в сформировавшемся у Китая в 1990-е гг. «комплексе внешнеполитических опасений» относительно возможности быть «окруженным» Соединенными Штатами Америки и их союзниками, «попасть в окружение» [43]. При этом Ф. Годман делает логичный вывод о том, что Китаю, несмотря на всю масштабность проекта, на деле «безразлично то, что лежит между ним и Европой», и деньги он тратит неохотно, избирательно и сообразно своим предпочтениям, но «делает символические жесты в адрес России в силу ее политической важности» [43]. Директор ECFR, британец М. Леонард высказывает опасение, что избыток новых международных инициатив на евразийском пространстве уже привел к «неразберихе», и для ЕС, прежде всего, важно всесторонне изучить и ОПОП, и ЕАЭС, и АБИИ, поскольку взаимодействие с такими структурами требует корпоративного подхода [29].

Научный сотрудник ECFR и германского Фонда Кёрбера А. Стэнцель подчеркивает, что Китай устроил в 2013-2015 гг. настоящую «пиар-кампанию» и «шумиху» вокруг ОПОП, но трансформировать его в нечто реально работающее - сложно, причем в силу объективных причин. Например, в Пакистане инфраструктурные проекты КНР продвигаются не настолько быстро, насколько хотелось бы, да и вопросы обеспечения безопасности проходящих через него маршрутов ОПОП отнюдь не решены. «Нарратив о Шелковом пути» использовался, как отмечает А. Стэнцель, еще Цзян Цзэминем для того, чтобы обосновать необходимость расширения экономического сотрудничества со странами Центральной Азии и других регионов мира. Однако главный вопрос - кто будет строить все планируемые шоссе, железные дороги и порты, создавая себе рабочие места и получая выгоду? И ответ на него, по сути, очевиден: 
конечно же, китайцы. Проблема лишь в том, пишет А. Стэнцель, что другие государства должны «не бежать за каждым предложением Китая, а детально оценивать, что отвечает лишь его краткосрочным либо долгосрочным интересам, а что может принести пользу и другим участникам» [42].

Примерно об этом же пишет и другой эксперт ECFR из Германии, А. Кратц. Она указывает на то, что Китай теперь «лепит ярлык компонента ОПОП на любой свой проект за рубежом», ведет в целом более активную внешнюю политику, и инфраструктурная составляющая ОПОП является чрезвычайно важной для всего внешнеполитического курса КНР. Китайская сторона предлагает с виду «лоукостерные» кредиты и инвестиционные проекты, однако для других стран, особенно для членов ЕС, «неразумно выстраиваться за ними в очередь», поскольку даже при низкой процентной ставке условия кредитов достаточно жесткие: они подразумевают участие китайских подрядчиков, которые часто завышают цены за свои услуги (и вся «лоукостерная» выгода от кредита сводится к нулю) и требуют для себя преференций и послаблений в сфере трудового законодательства, снабжения и экологических норм [28].

А. Стэнцель, продолжая тему, прослеживает расширение спектра проектов, охватываемых ОПОП, обретение им сетевой, кластерной природы, и высказывает еще более острую и скептическую оценку проекта, отмечая, что «Китай пытается создать вокруг инициативы “Пояса и пути” инклюзивный, но неубедительный нарратив», «которым Европу, без конкретных действий, убеждающих в его полезности, уже не купить» [41]. Заметим, что появление такой оценки, скорее всего, обусловлено тем, что 14-15 мая 2017 г. в Пекине был проведен первый официальный международный форум ОПОП, на который возлагалось много надежд участников проекта. Однако в итоге они не получили от китайской стороны ни конкретики по срокам и критериям успеха в реализации инициативы, ни разъяснения ее точных географических рамок, ни масштабного финансирования. Председатель КНР Си Цзиньпин заявил, что Китай готов вложить в инфраструктурные проекты ОПОП дополнительные 113 млрд долл. через
Фонд Шелкового пути, Азиатский банк инфраструктурных инвестиций и свои государственные банки развития, но эти институты еще не успели полностью потратить предыдущие транши, поскольку далеко не все соглашаются на их жесткие условия по возвратности средств и контролю над уже построенными объектами. В этих условиях, например, такая ведущая держава Азии, как Индия, и вовсе отказалась от дальнейшего участия в инициативе ОПОП, заявив, что это «колониальное предприятие», направленное на закабаление стран-участниц [4].

А. Стэнцель, в дополнение к скептическим оценкам перспектив ОПОП, уличает Китай в использовании проекта для культурной экспансии и в том, что китайская сторона развивает его исключительно сообразно своим принципам, оставаясь «глухой», например, к требованиям Германии включить в текст итогового коммюнике майского форума пункты о свободной торговле и честной конкуренции, а также к опасениям все той же Германии (вместе с Францией и Великобританией) относительно отсутствия должного внимания к социальным аспектам, защите окружающей среды и финансовой прозрачности. Именно поэтому три крупнейшие европейские державы отказались подписывать упомянутое коммюнике [41].

Наконец, к 2025 г. аналитики ECFR прогнозируют утверждение обновленного сухопутного Шелкового пути как «новой коммуникационной артерии» всего евразийского континента, которую «будут контролировать состоящие в прагматическом альянсе Китай, Иран, Россия и Турция» [19], а морской Шелковый путь тем временем способен стать «Планом Маршалла для Южной и Юго-Восточной Азии». Такое сравнение продиктовано уровнем влияния, которое КНР получает благодаря сооружению не только сухопутной, но и морской инфраструктуры, которую затем сможет использовать в своих целях [17].

Другой крупнейший в Европе «мозговой центр»-Стокгольмский институт исследований проблем мира (СИПРИ) - выпустил чрезвычайно обстоятельный доклад, посвященный ОПОП, в 2017 г. В нем детально рассматриваются географическая локализация проекта, его цели, мотивация Китая, влияние на безо- 
пасность в Центральной и Южной Азии, а также соотношение с интересами ЕС. Авторы доклада классифицируют ОПОП, как выражение видения Китаем инфраструктурного развития Евразии, ее транспортных связей и экономического сотрудничества. С одной стороны, как отмечается, инициатива может восполнить имевшуюся ранее нехватку инфраструктуры и систем многостороннего финансирования проектов. С другой - она не является действительно многосторонней, а работает на расширение стратегического политического и экономического влияния КНР. В то же время высказывается мнение, что китайская сторона переоценила свои возможности и недооценила геополитические трудности, с которыми неизбежно столкнется при строительстве ОПОП. Интересна высказываемая далее точка зрения о том, что по пути следования ОПОП, а именно в Центральной Азии, Китай, в соперничестве с Россией, несмотря на все свои финансовые вливания, уступает ей, поскольку на ее стороне - политическое, историческое и культурное единство с регионом и «доминирование в его архитектуре безопасности». Позитивные эффекты от реализации ОПОП в Центральной и Южной Азии возможны, как подчеркивается в докладе, только при условии качественного воплощения инициатив в жизнь и соблюдения различных аспектов человеческой безопасности (human security). Европейскому союзу СИПРИ рекомендует выстраивать тесное стратегическое партнерство с Китаем, Индией и Россией и использовать любые возможности для «калибровки» инициатив ОПОП в своих интересах, для чего необходимо выстраивать стратегическое планирование своей политики в Евразии и вкладывать как можно больше ресурсов в изучение ОПОП и происходящих в связи с ним процессов [24].

Небольшую, но достаточно серьезную и информативную коллективную монографию по ОПОП с участием экспертов из ЕС, России и Китая, выпустил в 2017 г. итальянский Институт исследований мировой политики (ISPI) [14]. Применительно к европейским авторам в ней стоит отметить разделы, написанные А. Амигини, Ф. Фасуло и В. Тэлбот (ISPI), а также К. Рише (Сорбонна) и Ж. Руэ (Университет Париж 13). А. Амигини отмечает, что после объявления о старте проекта ОПОП он оброс невероятным количеством спекуляций, в то время как его основные цели носят геополитический и стратегический характер. Китай за счет запуска ОПОП, с одной стороны, укрепляет свои взаимоотношения со странами Азии, в первую очередь - Центральной и Юго-Восточной, а с другой - получает «новые драйверы роста» для национальной экономики, для выравнивания уровня экономического развития разных регионов страны, а также рынки для экспорта товаров и услуг, прежде всего - строительных. Благодаря развитию инфраструктуры себестоимость доставки товаров из Китая снижается, что также работает на интересы китайских производителей. Параллельно обеспечивается стабильный импорт энергоресурсов. Еще одной важнейшей задачей, которую решает КНР с помощью ОПОП, является интернационализация юаня. Что касается партнеров Китая, то для них результаты отнюдь не столь впечатляющи, и сотрудничество далеко от пропагандируемой схемы «win-win»: у стран Центральной Азии уже сформировался огромный дефицит в торговле с КНР, и с развитием транспортной сети и увеличением торговли он только продолжит расти также, как и колоссальные объемы вывоза в Китай природных ресурсов из этих стран [14, p. 121-139].

Этим же автором высказывается ряд рекомендаций для ЕС в контексте взаимодействия с Китаем по проекту ОПОП. В частности, говорится о необходимости расширить двусторонний диалог на высшем уровне, соотносить с реалиями ОПОП собственную стратегию ЕС в отношении Центральной Азии и России; продумать схемы работы с китайскими инвесторами в случае увеличения инвестиций из КНР в рамках ОПОП, детально изучать и отслеживать развитие связей между Китаем и странами Центральной и Восточной Европы в формате «16+1» [14, p. 141-144].

В разделе, написанном К. Рише и Ж. Руэ в соавторстве с Ван Сешу, отмечается, что взаимодействие ЕС с Китаем носит стабильный характер, хотя не всегда осуществляется на выгодных для европейской стороны условиях. Однако развивать его, в том числе в рамках ОПОП, необходимо, прежде всего, в целях использования достижений глобализа- 
ции и совершенствования транспортной инфраструктуры в Европе и за ее пределами [14, p. 97-119].

Ф. Фасуло и В. Тэлбот акцентируют внимание на включении в ОПОП стран Ближнего Востока и Северной Африки. Отмечается значительное улучшение и большой потенциал китайско-турецкого взаимодействия, развитие взаимоотношений КНР и арабских стран. Наиболее успешным признается опыт сотрудничества КНР с Саудовской Аравией [14, p. 75-95].

Аналитический доклад, посвященный развитию взаимоотношений Китая и ЕС в контексте формирования «Пояса и пути», в 2017 г. выпустил крупнейший британский исследовательский центр «Chatham House». Основные акценты таковы: с одной стороны, ОПОП может привести к «бурному расцвету» торговли между двумя партнерами, а необходимость совершенствования инфраструктурной базы, отраженная в концепции ОПОП, созвучна «Плану Юнкера» по развитию ЕС на ближайшее время; с другой - китайский проект главным образом реализует интересы своих национальных производителей и является просто «инструментом» переноса избыточных производственных мощностей в другие страны. Также проект будет работать на развитие коммуникаций в финансовой сфере между Китаем и различными регионами мира и на интернационализацию юаня. Европейским политикам доклад советует задуматься о собственных (а не только китайских) инвестициях в рамках проекта, в том числе от частных инвесторов, поскольку только при их наличии возможно участвовать в управлении процессом [20].

Если говорить об индивидуальных исследованиях, то стоит уделить внимание целому ряду работ европейских авторов. Р. Пантуцци и А. Петерсен (Королевский Объединенный Институт оборонных исследований Великобритании) определяют интересы КНР в Центральной Азии в контексте ОПОП, как «эгоистичные», а саму инициативу - как нацеленную на получение доступа к природным ресурсам региона, экономический подъем Синьцзян-Уйгурского автономного района (СУАР) и повышение транспортной доступности европейского рынка для китайской стороны [34].
Также, по мнению Р. Пантуцци, Китай с помощью ОПОП и связанных с ним крупных инициатив пытается продемонстрировать свой «центральный статус в мировых делах». Главная же форма реализации проектов ОПОП (строительство инфраструктуры силами китайских компаний, получающих деньги из выданных ранее стране-реципиенту китайских кредитов) проста и уже отработана в Центральной Азии. Гораздо сложнее странам-участницам ОПОП найти способ использовать проект так, чтобы это были «не просто дороги, проходящие через их территорию». Как это сделать - на такой вопрос нет ответа, но есть понимание, что ОПОП - это не «гуманитарная помощь», а чисто «коммерческий» проект для Китая [33].

Британский эксперт Б. Даве (Лондонская Школа восточных и африканских исследований - SOAS) подходит к вопросу более масштабно и в то же время неожиданно просто, по сравнению с другими аналитиками. Она говорит, что в оценке ОПОП «нельзя брать в расчет только открытые стороны, также надо думать и о том, что существуют скрытые эффекты развития... Также надо учитывать такой момент: хотят ли все страны развиваться в том же направлении, что и Китай? Ведь некоторые из них преследуют другие цели развития» [8]. И действительно - почему-то, обсуждая китайский проект, созданный в Китае и для Китая, большинство аналитиков на этом не заостряют внимание. Хотя мы имеем дело с чрезвычайно амбициозной и продуманной стратегией, которая направлена на достижение одной цели - возвышения, усиления влияния КНР. Но вряд ли такими цивилизационными категориями мыслят многие страны, заинтересовавшиеся ОПОП. Скорее всего, они либо попросту надеются, что нацеленный на достижение своей «китайской мечты» Китай и с ними поделится какими-нибудь бонусами, либо не задавали себе вопроса, не сравнивали, что получает, используя в ОПОП их территорию и ресурсы, Китай, а что - они сами.

Р. Рампел из британского «Chatham House» анализирует реализацию крупнейшего инфраструктурного проекта КНР в рамках подключения к «Поясу и пути» африканских стран - строительство железной дороги в Ке- 
нии. Это первая железная дорога, построенная в Кении с 1901 г., но на поверку оказывается, что нужна она была, главным образом, тамошнему президенту, чтобы заработать популярность для переизбрания на второй срок. И то, популярность достаточно сомнительная, потому что долг по кредитам Китаю теперь, после завершения строительства дороги, составляет $6 \%$ (!) всего кенийского ВВП, а в процессе регулярно поступали жалобы на занижение стоимости отчуждаемой для строительства земли, отвратительные условия жизни и работы для рабочих-кенийцев (в отличие от сотрудников-китайцев), и к тому же целый ряд участков дороги был проложен через те зоны сохраняемой дикой природы, которые вообще затрагивать не следовало [37]. Пожалуй, это одна из наиболее ярких иллюстраций того, что проекты ОПОП не являются благотворительностью, а носят исключительно прагматичный характер и представляют собой просто схему зарабатывания денег китайскими компаниями и получения влияния в регионах мира китайским государством.

По мнению К. Брауна (также эксперта «Chatham House»), вызывает беспокойство недостаток информации и прозрачности относительно полного содержания ОПОП. Но ясно, что его замысел представляет собой «гибкий» план Китая и предполагает создание «общего экономического пространства». Также высказывается мнение, что ОПОП пригоден пока только для экономического диалога, но не для сотрудничества в сфере безопасности, поскольку у Китая и других стран различно понимание основных угроз [11].

Французская исследовательница К. Брюжье (Институт проблем безопасности ЕС EUISS) видит в качестве главных задач ОПОП для КНР, с одной стороны, «противовес российскому влиянию» и обустройство альтернативных маршрутов транзита своих товаров вне зависимости от России, а с другой - стратегию регионального экономического развития в нестабильном Синьцзян-Уйгурском автономном районе (СУАР) и способ обеспечить свою энергетическую безопасность [12].

М. Рудольф из германского Института Меркатора называет ОПОП «спекулятивным пузырем», главным проектом лично для председателя КНР Си Цзиньпина, и сомневается в том, что КНР сможет осуществить планируемые гигантские расходы в то время, когда эти средства нужны для ее собственного развития. Но, делает вывод немецкий эксперт, вместо модернизации своей экономики в части изменения действующей системы товарного перепроизводства Пекин выбрал простой экспорт производственных мощностей за рубеж и спекуляции на внешних рынках, к тому же еще и нестабильных (например, Пакистан). И, что интересно, формальные соглашения именно по ОПОП ему удалось заключить только с двумя государствами - Россией и Венгрией, что говорит о недоверии большинства потенциальных партнеров к проекту [36].

Экспертов Фонда Фридриха Эберта (Германия) в сложившейся ситуации интересует не только развитие торговых связей, но и вопрос о безопасности в Афганистане. В связи с этим ими отмечается, как положительная тенденция, создание трехстороннего формата сотрудничества «Китай - Афганистан - Пакистан», а относящийся к Шелковому пути экономический коридор «Китай - Пакистан», затрагивающий также и Афганистан, по их мнению, поможет «улучшить транспортную доступность региона и создать вдоль этого коридора различные промышленные производства» [9]. Что касается создания производств, отметим, что подобные ожидания представляются несколько завышенными, поскольку примеры инвестиций Китая в странах Центральной Азии, Латинской Америке и Африки показывают, что он навязывает крайне жесткие условия и преследует в первую очередь интересы своих подрядчиков, банков и т. д., в то время как страна-реципиент инвестиций приходит не к развитию собственного промышленного производства и технологического потенциала, а, наоборот, к примитивизации экономики (см., например: $[7 ; 10 ; 18])$.

По мнению К. Мюллер-Маркус из Центра международных исследований в Барселоне, инициатива ОПОП обусловлена отчасти тем, что Китай, с одной стороны, ищет «новые двигатели» своего развития, а с другой стремится к тому, чтобы транспортные пути и поставки его товаров не зависели ни от территориальных споров на морских просторах 
Азиатско-Тихоокеанского региона, ни от сотрудничества стран АТР с США. Таким образом будет постепенно формироваться «китаецентричная торговая сеть». Что касается участия в ОПОП ЕС, то, подобно другим европейским специалистам, К. Мюллер-Маркус также отмечает важный момент: Китай отдает предпочтение ведению переговоров в двустороннем формате, что отнюдь не способствует общеевропейскому единству [31].

Другой испанский исследователь, X.С. Гевара, обращает внимание на такой момент, как продолжение «Шелкового пути» в Африку, а именно использование Китаем портов Багамойо в Танзании и Момбасы в Кении для доставки увеличивающихся партий своих товаров. Постепенно получая контроль над отдельными портами и морскими маршрутами, Китай создает единую схему, в которую включены уже и греческий порт Пирей, и китайская база в Джибути, и маршруты в Индонезию и Прибалтику. Финансировать проекты в Африке будет Китайско-Африканский Фонд развития, созданный еще в 2009 г. и являющийся, по мнению испанского автора, точно таким же инструментом влияния КНР, как Азиатский банк инфраструктурных инвестиций или Фонд Шелкового пути. Также Х.С. Гевара приводит в качестве иллюстрации к опасениям относительно прозрачности проектов ОПОП актуальный, надо думать, для Испании случай с Мексикой, а именно случившийся там громкий коррупционный скандал в связи с выигранным КНР тендером на строительство высокоскоростной железнодорожной магистрали (добавим, что результаты тендера мексиканские власти под напором общественности и СМИ вынуждены были отменить [6]). Наиболее понятная выгода от участия в ОПОП для Испании видится испанскому исследователю в возможном посредничестве Испании в торговле между Китаем, Северной Африкой и Латинской Америкой [25].

Исследователи из научных центров Дании и Норвегии в основном занимаются мониторингом того, как Китай пытается продвигать свои интересы в Арктическом регионе, где его привлекают как значительные запасы сырьевых ресурсов, так и возможность использования транспортных путей, в том числе в системе маршрутов ОПОП.
Главным образом реализация этих интересов обеспечивается посредством участия КНР в качестве наблюдателя в Арктическом совете. Высказываются опасения, что большие объемы инвестиций в экономику скандинавских стран в сочетании с действиями китайского лобби в местных правительствах могут поставить под контроль КНР основные отрасли экономики, а в первую очередь, добычу стратегических видов сырья в датской Гренландии [5].

Определенный интерес представляют оценки ОПОП, высказанные экспертами аналитических центров стран Восточной Европы. По мнению С. Горака (Институт международных исследований Карлова университета Праги), ОПОП - «противовес и американской стратегии “Нового Шелкового пути” (о ней см. подробнее, например, [30]. - K. M.), и Евразийскому экономическому союзу. С его помощью Китай планирует вовлечь в долгосрочное экономическое сотрудничество государства Центральной Азии и Кавказа». При этом ОПОП, с точки зрения чешского исследователя, имеет выгодное отличие от ЕАЭС: он будет представлять из себя не «формальную» структуру, а совокупность сетевых связей политических, экономических, социальных, в том числе неформальных. Однако его цель оценивается однозначно: все эти связи строятся только «в интересах Китая» [26, p. 173174]. Исследователем проработан и вопрос о длительном и стратегическом характере китайского проекта: в своей статье, совместной с Й. Сиром и посвященной взаимоотношениям Китая с Туркменией, С. Горак подчеркивает, что инициатива возрождения Шелкового пути обсуждалась премьером Госсовета КНР Ли Пэном с его центрально-азиатскими коллегами еще в 1994 году [40, p. 77-78]. Также в данной работе содержится вывод о том, что главной составляющей ОПОП на современном этапе является обеспечение Китая энергоресурсами, прежде всего - центральноазиатским газом [40, p. 87]. Крайне важным именно энергетический компонент ОПОП считает и болгарский эксперт Ю. Попов, отмечая также, что ЕС следует уделить больше внимания изучению данного аспекта [35].

В. Семерак (Институт международных исследований Карлова университета Праги), 
выделяет особую роль в ОПОП зон свободной торговли КНР с соседними государствами (Пакистаном, Сингапуром, Австралией, Южной Кореей), партнерами в других регионах мира (Чили, Перу, Коста-Рикой, Исландией, Швейцарией) и международными организациями (АСЕАН). В ближайших планах Китая, как отмечает чешский исследователь, и это тоже будет использоваться в целях решения китайской стороной своих задач в ОПОП, - создание таких зон с Грузией и Молдавией. Главной мотивацией Китая в создании ОПОП, наряду с преодолением дисбалансов внутреннего развития, желанием добиться более комфортных условий для доставки своих товаров и использованием избыточных производственных мощностей, В. Семерак называет «прямые интересы влиятельных китайских ТНК». В связи с этим, как отмечается, возникают вопросы к тому, как будут приниматься решения о поддержке тех или иных проектов, которые могут предложить вовлеченные в сотрудничество с Китаем страны, и эффективности расходования фондов Азиатского банка инфраструктурных инвестиций. Координация всех проектов этой огромной инициативы затруднительна, что создает условия для коррупции и «развития поведения по модели рантье». Участие самой Чешской Республики в ОПОП, с одной стороны, может принести возможность заработать на реэкспорте китайских товаров в третьи страны, но с другой - еще более усилить асимметрию торгового баланса с Китаем, создать лишнюю конкуренцию для национальных производителей и почву для нецелевого расходования инвестиционных фондов. Для благосостояния государства эффект будет «нулевым». Единственный, кто может, по мнению В. Семерака, получить больше пользы, чем вреда от участия в ОПОП, - это наиболее бедные и находящиеся в сложной экономической ситуации страны Южной и Юго-Восточной Азии, такие, как Бангладеш, Пакистан и Камбоджа [38].

Из позиций, высказанных в аналитическом докладе польского Центра исследований Востока им. М. Карпа, можно отметить мнение о том, что «Пояс и путь» является демонстрацией амбиций КНР на международной арене. Указывается, что ОПОП симво- лизирует фундаментальные изменения в китайской внешней политике и ее переход к более активным действиям. Одновременно ОПОП представляет собой ответ китайского руководства на проблемы внутри страны (разрыв в уровне развития провинций и перепроизводство в промышленности) и на активную деятельность других акторов международных отношений на пространстве Евразии. Наконец, ОПОП классифицируется не как региональный блок, а как продвигаемое Китаем воплощение его видения глобализации, в противовес инициативам, прежде всего, США, Японии и России. При этом инициатива ОПОП является односторонней, и, хотя Китай не хочет ее институционализировать, уже ясно, что правила игры в ней, скорее всего, будет вырабатывать он один [27].

Находятся и те, кто оценивает ОПОП и участие в нем более позитивно, рассчитывая на бонусы для своих государств и, надо полагать, пытаясь показать их самоутверждение и самостоятельный курс в рамках ЕС. Так, например, оценивает ОПОП Т. Матура, профессор венгерского Университета «Корвинус» в Будапеште. Он, в частности, приветствует китайский проект строительства 350-километровой скоростной железной дороги из Белграда в Будапешт. Такой участок может стать важным звеном между Центральной Европой и дорогой к греческому порту Пирей, акции которого были ранее куплены КНР. Руководящие органы Евросоюза уже начали расследование по факту заключения Венгрией несогласованных с Брюсселем договоренностей, допускающих внешнего партнера к изменениям в столь серьезном сегменте транспортной сети ЕС, о чем в статье в том числе и упоминается. Однако Т. Матура настроен оптимистично: «Венгерский участок послужит как витрина того, что Китай способен построить, причем построить в соответствии со стандартами ЕС» [21].

Позитивно отзывается об ОПОП и греческий исследователь Г. Цогопулос: по его словам, проект «открывает дорогу для более глубокого сотрудничества между Грецией и КНР» (хотя, справедливости ради, стоит заметить, что «глубже» уже, в общем-то, некуда. Сам же Г. Цогопулос приводит данные о том, что Китай к настоящему моменту успел 
купить не только порт Пирей, как упоминалось выше, но и греческих государственных облигаций на 6 млн евро. В Пирей он отправляет примерно по 3 млн контейнеров в год и намерен получить контроль еще и над портом в Салониках). Отмечается, однако, что столь активное участие Греции в ОПОП позволяет ей привлекать больше китайских туристов, да и имидж у КНР и ее проектов в глазах греческого общества «более позитивный», чем у европейских соседей, например, у Германии. И даже создание Китаем целой ассоциации своих транснациональных корпораций, работающих в Греции («COSCO», «Huawei», «ZTE», «Air China») для греческой стороны - не повод для беспокойства антимонопольных служб, а «показатель заинтересованности Китая в том, чтобы больше инвестировать в Грецию» [44].

\section{Результаты}

Подведем итог. По результатам исследования можно сделать следующие выводы:

- в настоящее время в ЕС идет крайне серьезное, комплексное изучение ОПОП и активизируется исследование внешней политики Китая в целом, в силу повышения его роли в международных делах и интенсификации сотрудничества с европейской стороной;

- все работы европейских китаеведов по анализу ОПОП отличаются тщательной проработкой вопроса, объективным взглядом на проблему, высоким профессионализмом, подбором разнообразных источников для исследования. Нет однобоких оценок, отсутствуют чисто положительные или, наоборот, негативные подходы, скорее, анализ практически во всех случаях выдержан в одном ключе - объективном, взвешенном, учитывающем разные стороны проекта, с четким пониманием рисков, но в то же время рекомендациями для стран ЕС не покинуть проект, а стараться калибровать его и отстаивать только свою выгоду. Однозначно положительные оценки ОПОП немногочисленны и встречаются только в работах специалистов из стран Восточной Европы, то есть государств, объективно заинтересованных в привлечении любых китайских инвестиций или кредитов и определенном балансе сил против всех остальных внешних партнеров ЕС, США, России;

- большинство европейских синологов, изучавших развитие ОПОП, сходятся во мнении, что данный проект не является формой помощи КНР другим странам или более-менее равноправным партнерством, а представляет собой чисто коммерческое начинание и работает практически исключительно на китайские интересы, хотя специалистами стран Восточной Европы пока еще высказываются надежды на плодотворное для развития экономик их государств сотрудничество;

- отмечено, что ОПОП реализуется на основе достаточно простых и отработанных схем по экспорту Китаем (вместо модернизации и структурной перестройки своей экономики) производства, услуг и излишней продукции за рубеж, с использованием своих же банковских средств, которые, через оплату труда китайских подрядчиков, возвращаются китайской стороне;

- в качестве важных компонентов и мотивирующих факторов для КНР в строительстве ОПОП выделяются также энергетическая составляющая, обеспечение развития западных регионов страны с целью достижения в них социальной стабильности и выравнивания уровня жизни с более экономически развитыми восточными провинциями, получение доступа к сырьевым ресурсам стран Евразии и интернационализация юаня;

- учитываются европейскими экспертами и военно-политические аспекты китайского проекта: экспансионистский в геополитическом плане характер продвижения ОПОП, выгода от формирования новых транспортных маршрутов, позволяющих Китаю выйти из «окружения» союзников США в АТР, выдвижение условий обязательного контроля над построенными объектами, возможности использования в своих интересах сухопутной и особенно морской (портовой) инфраструктуры, возводимой в рамках ОПОП и соединяющейся в единую маршрутную сеть, включая в том числе Пакистан, Афганистан, Юго-Восточную Азию и Африку. Кстати, активного участия в разрешении серьезных и давних проблем безопасности в том же Афганистане КНР принимать вряд ли будет, уделяя приори- 
тетное внимание торговому и финансовому доминированию;

- ОПОП воспринимается, как проект, конкурирующий с интеграционными инициативами других стран на евразийском пространстве, в первую очередь, с Евразийским экономическим союзом. К планам «сопряжения» ЕАЭС и ОПОП эксперты европейских китаеведческих центров относятся скептически как в силу конкуренции между двумя проектами, так и в силу того, что подходы России и Китая к сопряжению и к двустороннему партнерству, в целом, существенно разнятся в плане задач, решаемых с помощью друг друга;

- выделяется ряд рисков в реализации ОПОП, связанных с нестабильностью в различных точках региона, а также с возможной переоценкой КНР своего финансового потенциала;

- в адрес руководства ЕС высказываются рекомендации более тщательной экспертизы планов участия европейской стороны в ОПОП и проведения четкого разграничения между теми проектами, в которых выгоду может получить один Китай, и возможными взаимовыгодными инициативами, которые нужно развивать в первую очередь.

Представляется, что все вышеперечисленное свидетельствует о важном сдвиге в динамике взаимоотношений европейских стран и КНР в целом. В отличие от европейских бизнесменов и политиков, готовых в погоне за быстрыми китайскими деньгами расставаться с крупными пакетами акций предприятий (см., например: [39]), допускать подрядчиков из КНР в стратегически важные отрасли (см., например, [13]) и в целом всемерно участвовать в том сообществе ОПОП, которое является, по сути, ведомым и должно будет работать на развитие Китая; у европейского научного сообщества за 4 года действия инициативы ОПОП сформировалось абсолютно рациональное и проработанное видение проекта, задач, которые планирует решить посредством его Китай, и рисков участия для различных стран. А развитие экспертизы и собственной стратегии в отношениях с просчитывающим свои шаги на десятилетия вперед Китаем является важнейшим условием для равноправного и взаимовыгодного сотрудничества любой страны или региона с ним в перспективе.
В том числе актуально это условие и для России, если она хочет на равных взаимодействовать с КНР, войдя в проект ОПОП. Кроме того, можно вынести и другие уроки из анализа работ европейских экспертов: в первую очередь - понять беспочвенность чрезмерно высоких ожиданий от китайского проекта и надежд на легкие китайские инвестиции. Последние при оценке эффективности проектов необходимо четко разделять на прямые (в создание, например, с нуля некоего производства) и портфельные (приобретение ценных бумаг), а кредиты и вовсе рассматривать отдельно, поскольку их объемы (как и количество проданных акций) трудно назвать показателем успешного сотрудничества. В условиях развития новых технологий, нового, по сути, витка индустриализации во всем мире и перехода многих стран к принципам «зеленой экономики» для участия в любом проекте и сотрудничестве должны быть четкие критерии эффективности в первую очередь не количественного, валового характера, а в плане продвижения страны и ее регионов вперед в области новых технологий, экологичности и социальной значимости любых начинаний и совместных инициатив.

\section{ПРИМЕЧАНИЕ}

${ }^{1}$ Работа выполнена при поддержке программы Европейского союза ERASMUS+ Jean Monnet, номер проекта 575043-EPP-1-2016-1-RU-EPPJMOCHAIR.

\section{СПИСОК ЛИТЕРАТУРЫ}

1. Габуев, А. Т. Шелковый путь в никуда / А. Т. Габуев. - Электрон. текстовые дан. - Режим доступа: https://www.vedomosti.ru/opinion/articles/ 2017/05/15/689763-shelkovii-put (дата обращения: 15.05.2017). - Загл. с экрана.

2. Денисов, И. Е. Шелковая безопасность: новая китайская концепция развития и правила игры в Евразии / И. Е. Денисов // Индекс безопасности. 2015. - Т. 21, № 3 (114). - С. 51-60.

3. Кашин, В. Б. Особый пояс - особый путь / В. Б. Кашин. - Электрон. текстовые дан. - Режим доступа: https://www.vedomosti.ru/opinion/articles/ 2017/05/30/692026-osobii-poyas (дата обращения: 31.05.2017). - Загл. с экрана.

4. Коростиков, М. Ю. Китай обещал опоясать полмира / М. Ю. Коростиков. - Электрон. тексто- 
вые дан. - Режим доступа: https://www.kommersant. ru/doc/3297741 (дата обращения: 17.05.2017). - Загл. с экрана.

5. Криворотов, А. К. Арктическая стратегия Китая: взгляд из Скандинавии / А. К. Криворотов // Китай в мировой и региональной политике. История и современность. - 2013. - Т. 18, № 18. С. $158-192$.

6. Мексика отменила сделку с Китаем на постройку железной дороги за $\$ 4,3$ млрд // Интерфакс. - 2014. - 7 нояб. - Электрон. текстовые дан. Режим доступа: http:/www.interfax.ru/business/ 405967 (дата обращения: 28.10.2017). - Загл. с экрана.

7. Савкович, Е. В. Торгово-экономическое сотрудничество КНР и Республики Узбекистан в 1990-х - середине 2000-х гг. / Е. В. Савкович // Вестник Томского государственного университета. - 2012. № 356. - С. 89-94.

8. Экспертные встречи: британский эксперт рассказала о последствиях реализации инициатив Шелкового пути // Казахстанский институт стратегических исследований при Президенте Республики Казахстан. - Электрон. текстовые дан. - Режим доступа: http://kisi.kz/ru/categories/events/posts/ ekspertnye-vstrechi-britanskij-ekspert-rasskazala-oposleds (дата обращения: 11.06.2017). - Загл. с экрана.

9. Afghanistan's Region: 2014 \& Beyond. Berlin : Friedrich Ebert Stiftung, 2014. - 22 p.

10. Brautigam, D. The Dragon's Gift. The Real Story of China in Africa / D. Brautigam. - Oxford : Oxford University Press, 2009. - 414 p.

11. Brown, K. The Security Implications of China's Belt and Road / K. Brown // The Diplomat. 2015. - 27 Nov. - Electronic text data. - Mode of access: http://thediplomat.com/2015/11/the-securityimplications-of-chinas-belt-and-road/ (date of access: 10.01.2016). - Title from screen.

12. Brugier, C. China's way: the new Silk Road / C. Brugier // European Union Institute for Security Studies Brief Issue. - 2014. - № 14. - P. 1-4.

13. China plans central role in UK nuclear industry after Hinkley Point approval // The Guardian. - 2016. - 15 Sept. - Electronic text data. Mode of access: https://www.theguardian.com/ business/2016/sep/15/hinkley-point-chinese-firm-tosubmit-essex-nuclear-plant-plans (date of access: 07.07.2017). - Title from screen.

14. China's Belt and Road: A Game Changer?Milano : ISPI, 2017. - 150 p.

15. China's investment in influence: the future of 16+1 cooperation // European Council on Foreign Relations. - 2016. - 14 Dec. - Electronic text data. Mode of access: http:/www.ecfr.eu/publications/ summary/chinas_investment_in_influence_the future_of_161_cooperation $7 \overline{2} 04$ (date of access: 05.07.2017). - Title from screen.
16. Connectivity Wars. Why Migration, Finance and Trade are the Geo-Economic Battlegrounds of the Future. - London : ECFR, 2016. - 224 p.

17. Danger on the High Seas: the East Asian Security Challenge // European Council on Foreign Relations. - 2016. - Electronic text data. - Mode of access: http://www.ecfr.eu/page/-/Danger_on_the High_Seas_An_East_Asian_Security_Challenge.pdf (date of access: 05.07.2017). - Title from screen.

18. Dosch, J. China and Latin America: Complementarity, Competition and Globalisation / J. Dosch, D. Goodman // Journal of Current Chinese Affairs. - 2012. - № 1. - P. 3-19.

19. Eight Scenarios for the EU in 2025 // European Council on Foreign Relations. - Electronic text data. Mode of access: http://www.ecfr.eu/specials/ rethinking_european_futures (date of access: 05.07.2017). - Title from screen.

20. EU-China Economic Relations to 2025: Building a Common Future// Chatham House. - 2017. Electronic text data. - Mode of access: https:// www.chathamhouse.org/ sites/files/chathamhouse/ publications/research/2017-09-13-eu-china-economicrelations-2025-garcia-herrero-kwok-liu-summerszhang-final.pdf(date of access: 06.11.2017). - Title from screen.

21. EU sets collision course with China over 'Silk Road' rail project // The Financial Times. - 2017. 20 Feb. - Electronic text data. - Mode of access: https:// www.ft.com/content/003bad14-f52f-11 e6-95eef14e55513608 (date of access: 22.02.2017). - Title from screen.

22. Eurasian integration: Caught between Russia and China // European Council on Foreign Relations. 2016. - 7 Jun. - Electronic text data. - Mode of access: http://www.ecfr.eu/article/essay_eurasian (date of access: 05.07.2017). - Title from screen.

23. Explaining China's Foreign Policy Reset // European Council on Foreign Relations. - 2015. 14 Apr. - Electronic text data. - Mode of access: http:// www.ecfr.eu/publications/summary/explaining_ chinas_foreign_policy_reset3001 (date of access: 12.01.2016). - Title from screen.

24. Ghiasy, R.The Silk Road Economic Belt / R. Ghiasy, J. Zhou. - Solna : SIPRI, 2017. -76 p.

25. Guevara, J. S. La estrategia China de "Una Franja, Una Ruta", posibles consecuencias para España, y oportunidades para las empresas españolas / J. S. Guevara // Boletín económico de ICE. - 2016. 1-29 Feb. - Electronic text data. - Mode of access: http://www.iberchina.org/files/2016/obor_serra. pdf (date of access: 28.10.2017). - Title from screen.

26. Horak, S. Challenges from the East: China / S. Horak // Putin's Grand Strategy: The Eurasian Union and Its Discontents. - Washington : John Hopkins University, Silk Road Studies Program, 2014. - P. 166-178. 
27. Kaczmarski, M. 'Silk Globalisation'. China's Vision of International Order / M. Kaczmarski. Warsaw : OSW, 2016. -28 p.

28. Kratz, A. Paying the China price: the costs of Chinese investment / A. Kratz // European Council on Foreign Relations. - 2015. - 20 Jul. - Electronic text data. - Mode of access: http://www.ecfr.eu/article/ commentary_paying_the_china_price_the_costs of chinese investment3074 (date of access: 27.12.2015). - Title from screen.

29. Leonard, M. A vision for the EU's new foreign policy strategy / M. Leonard // European Council on Foreign Relations. - 2015. - 24 Apr. - Electronic text data. - Mode of access: http://www.ecfr.eu/article/ commentary_a_vision_for the eus_new foreign policy strategy3006 (date of access: 05.07.2017). Title from screen

30. McBride, J. Building the New Silk Road / J. McBride// Council on Foreign Relations. - 2015. Electronic text data. - Mode of access: https://www. cfr.org/backgrounder/building-new-silk-road (date of access: 07.07.2017). - Title from screen.

31. Müller-Markus, C. One Belt, One Road: el sueño chino y su impacto sobre Europa / C. MüllerMarkus // Barcelona Centre for International Affairs. 2016, May. - Electronic text data. - Mode of access: https://www.cidob.org/publicaciones/serie_de_ publicacion/notes_internacionals/n1_148_one belt_one_road_el_sueno_chino_y_su_impacto_sobre_ europa/one_belt_one_road_el_sueno_chino_y_su_ impacto_sobre_europa (date of access: 28.10 .2017$)$. Title from screen.

32. “One Belt, One Road”: China's Great Leap Forward // European Council on Foreign Relations. 2015. - 10 Jun. - Electronic text data. - Mode of access: http://www.ecfr.eu/publications/summary/one belt_one_road_chinas_great_leap_outward3055 (date of access: 12.01.2016). - Title from screen.

33. Pantucci, R. China: Understanding Beijing's Belt and Road Initiative / R. Pantucci // Royal United Service Institute. - 2017. - 12 May. - Electronic text data. - Mode of access: https://rusi.org/commentary/ china-understanding-beijing $\% \mathrm{E} 2 \% 80 \% 99$ s-belt-and-roadinitiative (date of access: 05.07.2017). - Title from screen.

34. Pantucci, R. Tightening the Silk Road Belt / R. Pantucci, A. Petersen // The Diplomat. - 2013. 18 Sep. - Electronic text data. - Mode of access: http:// thediplomat.com/2013/09/tightening-the-silk-road-belt/ (date of access: 24.07.2014). - Title from screen.

35. Popov, J. Looking outwards: Expanding Europe's energy policy/ J. Popov // European Council on Foreign Relations. -2015. - 23 Jul.- Electronic text data. - Mode of access: http://www.ecfr.eu/article/ commentary_looking_outwards_expanding_europes energy_policy3078 (date of access: 05.07.2017). - Title from screen.
36. Rudolf, M. China's 'Silk Road' Initiative Is at Risk of Failure / M. Rudolf // The Diplomat. - 2015. 24 Sept. - Electronic text data. - Mode of access: http:// thediplomat.com/2015/09/chinas-silk-road-initiative-isat-risk-of-failure/ (date of access: 10.01.2016). - Title from screen.

37. Rumpel, R. Lessons from Kenya's New, Chinese-funded Railway / R. Rumpel // Chatham House. -2017. - 20 Jun. - Electronic text data. - Mode of access: https://www.chathamhouse.org/expert/ comment/lessons-kenya-s-new-chinese-fundedrailway (date of access: 06.11.2017). - Title from screen.

38. Semerák, V. One Belt, One Road - Czech Perspective / V. Semerák. - Electronic text data. - Mode of access: https://www.researchgate.net/publication/ 291337745_One_Belt_One_Road_-_Czech_Perspective (date of access: 26.10.2017). - Title from screen.

39. Shepard, W. China Hits Record High M\&A Investments In Western Firms / W. Shepard // Forbes. 2016. - 10 Sept. - Electronic text data. - Mode of access: https://www.forbes.com/sites/wadeshepard/ 2016/09/10/from-made-in-china-to-owned-by-chinachinese-enterprises-buying-up-western-companiesat-record-pace/\#683cd5665d87 (date of access: 07.07.2017). - Title from screen.

40. Sir, J. China as an Emerging Superpower in Central Asia: The View from Ashkhabad / J. Sir, S. Horak // China and Eurasia Forum Quarterly. - 2008. - Vol. 6, № 2. - P. 75-88.

41. Stanzel, A. China's Belt and Road-new name, same doubts? / A. Stanzel // European Council on Foreign Relations. - 2017. - 19 May. - Electronic text data. - Mode of access: http://www.ecfr.eu/article/ commentary_chinas_belt_and_road_new_name_ same_doubts (date of access: 05.07.2017). - Title from screen.

42. Stanzel, A. China's silk road to nowhere? / A. Stanzel // European Council on Foreign Relations. 2015. - 13 May. - Electronic text data. - Mode of access: http://www.ecfr.eu/article/commentary_ chinas silk_road to nowhere3025 (date of access: 27.12.2015). - Title from screen.

43. The Race for Eurasia: the EU in the face of Chinese and Russian integration projects // European Council on Foreign Relations. - 2016. - 18 Oct. Electronic text data. - Mode of access: http://www. ecfr.eu/events/event/the_race_for_eurasia_the_eu in_the_face_of_chinese_and_russian_integration (date of access: 05.07 .2017 ). - Title from screen.

44. Tzogopoulos, G. Greece: Perspectives on Eurasian integration / G. Tzogopoulos // European Council on Foreign Relations. - 2016. - 8 Jun. Electronic text data. - Mode of access: http://www. ecfr.eu/article/essay_eurasian_integration_greece (date of access: 05.07.2017). - Title from screen. 


\section{REFERENCES}

1. Gabuev A.T. Shelkovyy put v nikuda [Silk Road to Nowhere]. URL: https://www.vedomosti.ru/ opinion/articles/2017/05/15/689763-shelkovii-put. (accessed 15 May 2017).

2. Denisov I.E. Shelkovaya bezopasnost: novaya kitayskaya kontseptsiya razvitiya i pravila igry v Evrazii [Silk Security: a New Chinese Conception of Development and Game Rules in Eurasia]. Indeks bezopasnosti [Security Index], 2015, vol. 21, no. 3 (114), pp. 51-60.

3. Kashin V.B. Osobyy poyas - osobyy put [Special Belt - Special Road]. URL: https://www. vedomosti.ru/opinion/articles/2017/05/30/692026osobii-poyas. (accessed 31 May 2017).

4. Korostikov M.Yu. Kitay obeshchal opoyasat polmira [China Promised to Belt Half of the World]. URL: https://www.kommersant.ru/doc/3297741. (accessed 17 May 2017).

5. Krivorotov A.K. Arkticheskaya strategiya Kitaya: vzglyad iz Skandinavii [China's Arctic Strategy: a View from Scandinavia]. Kitay $v$ mirovoy $i$ regionalnoy politike. Istoriya i sovremennost, 2013, vol. 18 , no. 18 , pp. 158-192.

6. Meksika otmenila sdelku s Kitaem na postroyku zheleznoy dorogi za $\$ 4,3$ mlrd [Mexico Cancelled the \$4,3 Billion Railroad Construction Contract with China]. Interfax Agency, 2014, November 7. URL: http:// www.interfax.ru/business/405967 (accessed 28 October 2017).

7. Savkovich E.V. Torgovo-ekonomicheskoe sotrudnichestvo KNR i Respubliki Uzbekistan v 1990-kh - seredine 2000-kh gg. [Peoples Republic of China and Uzbekistan: Trade Cooperation in 1990s and early 2000s]. Tomsk State University Journal, 2012, no. 356, pp. 89-94.

8. Ekspertnye vstrechi: britanskiy ekspert rasskazala o posledstviyakh realizatsii initsiativ Shelkovogo puti [Expert Meetings: British Expert Described the Consequences of Silk Road Initiative]. Kazakh Institute of Strategic Studies. URL: http://kisi. $\mathrm{kz} / \mathrm{ru} /$ categories/events/posts/ekspertnye-vstrechibritanskij-ekspert-rasskazala-o-posleds (accessed 11 June 2017).

9. Afghanistan's Region: 2014 \& Beyond. Berlin, Friedrich Ebert Stiftung, 2014. 22 p.

10. Brautigam D. The Dragon's Gift. The Real Story of China in Africa. Oxford, Oxford University Press, 2009. 414 p.

11. Brown K. The Security Implications of China's Belt and Road. The Diplomat, 2015, November 27. URL: http://thediplomat.com/2015/11/the-security-implicationsof-chinas-belt-and-road/ (accessed 10 January 2016).

12. Brugier C. China's way: the new Silk Road. European Union Institute for Security Studies Brief Issue, 2014, no. 14, pp. 1-4.
13. China plans central role in UK nuclear industry after Hinkley Point approval. The Guardian, 2016, September 15. URL: https://www.theguardian.com/ business/2016/sep/15/hinkley-point-chinese-firm-tosubmit-essex-nuclear-plant-plans (accessed 7 July 2017).

14. China's Belt and Road: A Game Changer? Milano, ISPI, 2017. $150 \mathrm{p}$.

15. China's investment in influence: the future of $16+1$ cooperation. European Council on Foreign Relations, 2016, December 14. URL: http:// www.ecfr.eu/publications/summary/chinas investment_in_influence the future_of_161_cooperation 7204 (accessed 5 July 2017).

16. Connectivity Wars. Why Migration, Finance and Trade are the Geo-Economic Battlegrounds of the Future. London, ECFR, 2016. 224 p.

17. Danger on the High Seas: the East Asian Security Challenge. European Council on Foreign Relations, 2016. URL: http://www. ecfr.eu/page/-/Danger _on_the_High_Seas_An_East_Asian_Security_ Challenge.pdf(accessed 5 July 2017).

18. Dosch J., Goodman D. China and Latin America: Complementarity, Competition and Globalisation. Journal of Current Chinese Affairs, 2012, no. 1, pp. 3-19.

19. Eight Scenarios for the EU in 2025. European Council on Foreign Relations. URL: http:// www.ecfr.eu/specials/rethinking_european_futures (accessed 5 July 2017).

20. EU-China Economic Relations to 2025: Building a Common Future. Chatham House, 2017. URL: https:// www.chathamhouse.org/sites/files/ chathamhouse/publications/research/2017-09-13-euchina-economic-relations-2025-garcia-herrero-kwokliu-summers-zhang-final.pdf (accessed 6 November 2017).

21. EU sets collision course with China over 'Silk Road' rail project. The Financial Times, 2017, February 20. URL: https://www.ft.com/content/ 003bad14-f52f-11 e6-95ee-f14e55513608 (accessed 22 February 2017).

22. Eurasian integration: Caught between Russia and China. European Council on Foreign Relations, 2016, June 7. URL: http://www.ecfr.eu/article/ essay_eurasian (accessed 5 July 2017).

23. Explaining China's Foreign Policy Reset. European Council on Foreign Relations, 2015, April 14. URL: http://www.ecfr.eu/publications/summary/ explaining_chinas_foreign_policy_reset3001 (accessed 12 January 2016).

24. Ghiasy R., Zhou J. The Silk Road Economic Belt. Solna, SIPRI, 2017.76 p.

25. Guevara J.S. La estrategia China de "Una Franja, Una Ruta", posibles consecuencias para Espaca, y oportunidades para las empresas espacolas. 
Boletín económico de ICE, 2016, 1-29 Febrero. URL: http://www.iberchina.org/files/2016/obor_serra.pdf (accessed 28 October 2017).

26. Horak S. Challenges from the East: China. Putin's Grand Strategy: The Eurasian Union and Its Discontents. Washington, John Hopkins University, 2014, pp. 166-178.

27. Kaczmarski M. 'Silk Globalisation'. China 's Vision of International Order. Warsaw, OSW, 2016. $28 \mathrm{p}$.

28. Kratz A. Paying the China price: the costs of Chinese investment. European Council on Foreign Relations, 2015, July 20. URL: http://www.ecfr.eu/ article/ commentary_paying_the_china_price_the costs_of_chinese_investment 3074 (accessed 27 December 2015).

29. Leonard M. A vision for the EU's new foreign policy strategy. European Council on Foreign Relations, 2015, April 24. URL: http://www.ecfr.eu/ article/ commentary_a_vision_for_the_eus_new foreign_policy_strategy3006 (accessed 5 July 2017).

30. McBride J. Building the New Silk Road. Council on Foreign Relations. 2015. URL: https:// www.cfr.org/backgrounder/building-new-silk-road (accessed 7 July 2017).

31. Mbller-Markus C. One Belt, One Road: el sueco chino y su impacto sobre Europa. Barcelona Centre for International Affairs, May 2016. URL: https://www.cidob.org/publicaciones/ serie_de_publicacion/notes_internacionals/n1_148 one_belt_one_road_el_sueno_chino_y_su_impacto_sobre_ europa/one_belt_one_road_el_sueno_chino_y_su_ impacto_sobre_europa (accessed 28 October 2017).

32. "One Belt, One Road": China's Great Leap Forward. European Council on Foreign Relations, 2015, June 10. URL: http://www.ecfr.eu/publications/ summary/one_belt_one_road_chinas_great_leap_ outward3055 (accessed 12 January 2016).

33. Pantucci R. China: Understanding Beijing's Belt and Road Initiative. Royal United Service Institute, 2017, May 12. URL: https://rusi.org/ commentary/ china-understanding-beijing $\% \mathrm{E} 2 \% 80 \%$ 99s-belt-and-road-initiative (accessed 5 July 2017).

34. Pantucci R., Petersen A. Tightening the Silk Road Belt. The Diplomat, 2013, September 18. URL: http://thediplomat.com/2013/09/tightening-the-silkroad-belt/ (accessed 24 July 2014).

35. Popov J. Looking outwards: Expanding Europe's energy policy. European Council on
Foreign Relations, 2015, July 23. URL: http://www. ecfr.eu/article/ commentary_looking_outwards expanding_europes_energy_policy3078 (accessed 5 July 2017).

36. Rudolf M. China's 'Silk Road' Initiative Is at Risk of Failure. The Diplomat, 2015, September 24. URL: http:/ /thediplomat.com/2015/09/chinas-silk-road-initiative-isat-risk-of-failure/ (accessed 10 January 2016).

37. Rumpel R. Lessons from Kenya's New, Chinese-funded Railway. Chatham House, 2017, June 20. URL: https://www.chathamhouse.org/expert/ comment/lessons-kenya-s-new-chinese-fundedrailway (accessed 6 November 2017).

38. Semerok V. One Belt, One Road - Czech Perspective. 2015. URL: https://www.researchgate.net/ publication/291337745_One_Belt_One_Road__Czech_Perspective (accessed 26 October 2017).

39. Shepard W. China Hits Record High M\&A Investments in Western Firms. Forbes, 2016, September 10. URL: https://www.forbes.com/sites/ wadeshepard/2016/09/10/from-made-in-china-toowned-by-china-chinese-enterprises-buying-upwestern-companies-at-record-pace/\#683cd5665d87 (accessed 7 July 2017).

40. Sir J., Horak S. China as an Emerging Superpower in Central Asia: The View from Ashkhabad. China and Eurasia Forum Quarterly, 2008, vol. 6, no. 2, pp. $75-88$.

41. Stanzel A. China's Belt and Road - new name, same doubts? European Council on Foreign Relations, 2017, May 19. URL: http://www.ecfr.eu/ article/commentary_chinas_belt_and_road_ new name_same_doubts (accessed 5 July 2017).

42. Stanzel A. China's silk road to nowhere? European Council on Foreign Relations, 2015, May 13. URL: http://www.ecfr.eu/article/commentary chinas_silk_road_to_nowhere3025 (accessed 27 December 2015).

43. The Race for Eurasia: the EU in the face of Chinese and Russian integration projects. European Council on Foreign Relations, 2016, October 18. URL: http://www.ecfr.eu/events/event/the_race_for eurasia_the_eu_in_the face_of_chinese_and_russian integration (accessed 5 July 2017).

44. Tzogopoulos G. Greece: Perspectives on Eurasian integration. European Council on Foreign Relations, 2016, June 8. URL: http://www.ecfr.eu/ article/ essay_eurasian_integration_greece (accessed 5 July 2017). 


\section{Information about the Author}

Kseniya G. Muratshina, Candidate of Sciences (History), Associate Professor, Department of Theory and History of International Relations, Ural Federal University named after the first President of Russia B.N. Eltsin, Prosp. Lenina, 51, 620000 Ekaterinburg, Russian Federation, ksenia.muratshina@urfu.ru, https://orcid.org/0000-0001-7952-6299

\section{Информация об авторе}

Ксения Геннадьевна Муратшина, кандидат исторических наук, доцент кафедры теории и истории международных отношений, Уральский федеральный университет имени первого Президента России Б.Н. Ельцина, просп. Ленина, 51, 620000 г. Екатеринбург, Российская Федерация, ksenia.muratshina@urfu.ru, https://orcid.org/0000-0001-7952-6299 